\title{
X-linked Severe Combined Immunodeficiency \\ Diagnosis in Males with Sporadic Severe Combined Immunodeficiency and Clarification of Clinical Findings
}

\author{
Mary Ellen Conley, Rebecca H. Buckley, Richard Hong, Celine Guerra-Hanson, Chaim M. Roifman, \\ Joel A. Brochstein, Savita Pahwa, and Jennifer M. Puck \\ University of Tennessee College of Medicine and St. Jude Children's Research Hospital, Memphis, Tennessee 38101; Duke University \\ School of Medicine, Durham, North Carolina 27710; University of Wisconsin, Madison, Wisconsin; Baylor College of Medicine, \\ Houston, Texas 77030; Hospital for Sick Children, Toronto, Ontario, Canada; Memorial Sloan-Kettering Cancer Center, New York \\ 10021; Cornell University Medical College, Manhasset, New York 11030; and University of Pennsylvania School of Medicine, \\ Philadelphia, Pennsylvania 19104
}

\begin{abstract}
Over $80 \%$ of infants with severe combined immunodeficiency (SCID) of unknown genetic etiology are males, yet less than a third of these affected males have a family history of X-linked disease. To help identify new mutations of the X-linked SCID gene and to provide genetic counseling, $X$ chromosome inactivation patterns in $T$ cells from 16 women who had sons with sporadic SCID were examined. Between 9 and 35 human/ hamster hybrids that selectively retained the active human $X$ chromosome were produced from the $T$ cells of each woman and analyzed with an $\mathrm{X}$-linked restriction fragment length polymorphism for which the woman in question was heterozygous. Exclusive use of a single $X$ as the active $X$ was seen in the $T$ cell hybrids from 7 of the 16 women, identifying these women as carriers of X-linked SCID. Studies on additional family members confirmed the mutant nature of the inactive $X$ and revealed the source of the new mutation in three families. To determine whether there were any laboratory characteristics that might differentiate the boys whose mothers were identified as carriers of X-linked SCID from those whose mothers were not, the clinical records of both groups were compared to each other and to a group of 14 boys with a family history of X-linked SCID. The most consistent finding in the 21 patients with X-linked SCID was an elevated proportion of $B$ cells. These data demonstrate the high incidence of spontaneous mutation for the X-linked SCID gene and help clarify the characteristic presenting features of this disorder. ( $J$. Clin. Invest. 1990. 85:1548-1554.) immunodeficiency • genetic counseling $\cdot T$ cells $\bullet B$ cells $\cdot X$ chromosome
\end{abstract}

\section{Introduction}

Severe combined immunodeficiency (SCID) ${ }^{1}$ is a term used to describe a heterogeneous group of genetic disorders in which there are profound defects in both cellular and humoral im-

Address reprint requests to Dr. M. E. Conley, Department of Immunology, St. Jude Children's Research Hospital, 332 N. Lauderdale, Memphis, TN 38101.

Received for publication 13 September 1989 and in revised form 30 November 1989.

1. Abbreviations used in this paper: HPRT, hypoxanthine phosphoribosyltransferase; RFLP, restriction fragment length polymorphism; SCID, severe combined immunodeficiency.

J. Clin. Invest.

(C) The American Society for Clinical Investigation, Inc. 0021-9738/90/05/1548/07 \$2.00

Volume 85, May 1990, 1548-1554 munity (1-3). In North America, 20\% of affected infants have inherited autosomal recessive defects in production of adenosine deaminase or purine nucleoside phosphorylase (4, 5). An autosomal recessive defect in the expression of histocompatibility antigens accounts for an additional $2-5 \%$ of patients (6). In the remaining patients, the abnormal or absent gene product has not yet been identified, but the observation that affected males outnumber females by a ratio of $\sim 4: 1$ ( 1 , 2) suggests that a high percentage of cases may be due to defects inherited on the $\mathrm{X}$ chromosome. However, only $\sim 20-30 \%$ of affected boys have a family history of immunodeficiency and there are no clinical or laboratory findings that distinguish X-linked SCID from most autosomal recessive forms of the disease. Most children with SCID have markedly reduced numbers of $T$ cells, absent proliferative responses to mitogens, hypogammaglobulinemia, and normal or elevated numbers of B cells (1-3). These findings have made it difficult to classify patients in studies investigating the nature of the gene defects that cause SCID. In addition, it has been difficult to provide genetic counseling for families with a male affected with SCID.

We have recently developed a technique that identifies women who carry the gene for X-linked SCID (designated SCIDX 1 by the human genome-mapping committee [7]). This technique is based on the observation that the obligate carriers of X-linked SCID have preferential use of the normal, nonmutant $X$ as the active $X$ in $T$ and $B$ cells, the cell lineages primarily affected by the gene defect $(8,9)$. To help identify males with X-linked SCID, provide more information to women at risk, and learn more about the source of new mutations that result in X-linked SCID, we have used this technique to study 16 women who have had sons with SCID but who have no other family history of this disorder. The information gained from this study was then used to separate the patients with sporadic SCID into two groups: $(a)$ patients with X-linked SCID inherited from a carrier mother and $(b)$ patients with an autosomal recessive form of SCID or a new mutation of the $\mathrm{X}$-linked SCID gene. The clinical records of these two groups were then compared to each other and to those of a group of patients with a family history of $\mathrm{X}$-linked severe combined immunodeficiency in an attempt to find clinical or laboratory characteristics that would distinguish patients with X-linked SCID from those with other forms of the disease.

\section{Methods}

Subjects. The subjects of this study, the mothers of boys with sporadic SCID and their affected sons, were recruited through immunodeficiency clinics and genetic counseling services throughout the country. 
Patients born after 1976 were known to have normal adenosine deaminase and purine nucleoside phosphorylase activity. To avoid bias, no families were excluded because of an atypical laboratory presentation of SCID. Each mother-son pair was assigned a number at entry to the study. After informed consent was obtained, heparinized venous blood was drawn from the mother and sent to Philadelphia by Federal Express. Data on patients with a family history of X-linked SCID were retrieved from medical records or from the literature. A patient was identified as having a family history of X-linked SCID only if he had affected maternal uncles or cousins. Patients 17 and 18 in Table II are uncle and nephew; the remaining patients are from unrelated families. We have analyzed $\mathrm{X}$ chromosome inactivation patterns in $\mathrm{T}$ cells from obligate carriers from 10 of the 13 families represented in Table II. In all cases, the $\mathrm{T}$ cells demonstrated nonrandom $\mathrm{X}$ chromosome inactivation, thus confirming the diagnosis.

Cell separations and production of somatic cell hybrids. $\mathrm{T}$ cell hybrids were produced as previously described $(8-10)$. Briefly, peripheral blood lymphocytes were cultured with PHA for $3 \mathrm{~d}$, washed, and then cultured for an additional $3 \mathrm{~d}$ with IL-2 (Electro-Nucleonics, Inc., Silver Springs, MD). The activated T cells, which were $>97 \%$ positive for $\mathrm{CD} 3$, were then fused to cells from the hypoxanthine phosphoribosyltransferase (HPRT)-deficient Chinese hamster cell line, RJK88, using polyethylene glycol. The hybrids were grown in selective media so that only those hybrids that had retained the active human $\mathrm{X}$ chromosome to provide the HPRT were able to survive.

For methylation analysis, peripheral blood lymphocytes were further separated into $\mathrm{T}$ and $\mathrm{B}$ cells by sheep red blood cell-rosetting techniques (9). The T cells were stimulated with PHA and IL-2 as described above, whereas the B cells were infected with Epstein Barr virus and grown in multiple aliquots as previously described (9). Neutrophils for this experiment were harvested from the red blood cell pellet after Ficoll Hypaque centrifugation.

DNA analysis. The preparation of high molecular weight DNA, digestion of DNA using restriction enzymes, electrophoresis, and Southern blotting were performed as previously described (8). The probe chosen for each hybrid experiment was one for which the woman in question was heterozygous. Probes included in this study and the loci recognized by these probes are: 19-2, DXS3; L128, DXS7; 36B-2, DXS10; St-14, DXS52; p8, DXS1; St-1, DXS86; PDP34, DXYS1; and HPRT (7). DNA for methylation analysis was digested with Bgl I, Bgl II, and Eco RI alone or Bgl I, Bgl II, and Eco RI plus the methylation-sensitive enzyme Hpa II according to the technique described by Vogelstein et al. (11).

Statistics. Statistical analysis was performed using a maximum likelihood ratio test. The odds ratio reported represents the probability that the pattern of $\mathrm{X}$ inactivation observed in hybrids was a result of negative selection as compared with the probability of the null hypothesis of random $\mathrm{X}$ inactivation. The latter was modeled as a normal distribution in which $50 \%$ of the hybrids had the paternal $\mathrm{X}$ active with a SD of $21 \%$, estimated from T cell hybrid assays in 50 control women. An odds ratio of $>40: 1$ was considered indicative of negative selection, whereas a ratio of $<3: 1$ was considered evidence of random $\mathrm{X}$ chromosome inactivation.

Laboratory studies. The complete blood counts, serum immunoglobulin concentrations, lymphocyte surface markers, and mitogen responses were performed in several different laboratories using a variety of standard techniques. The results of these studies were obtained from patient charts or from published cases.

\section{Results}

The $\mathrm{X}$ chromosome inactivation patterns in $\mathrm{T}$ cell hybrids from 16 unrelated women were studied. 14 of the women had one son with SCID and two women (mothers 11 and 15) had two sons with SCID; none had other affected family members. Between 9 and 35 T cell hybrids, each containing the active human X chromosome, were harvested from each experiment and then analyzed with an X-linked restriction fragment length polymorphism (RFLP) for which the woman in question was heterozygous. The results, as shown in Table I, demonstrated that $T$ cell hybrids from 7 of the 16 women exhibited exclusive use of a single $X$ as the active $X$, with a high likelihood, $\geq 50: 1$, that the pattern represented skewing due to negative selection rather than normal randomization. The $X$ chromosome inactivation pattern thus established the nature of the genetic defect in these women's affected sons. Representative Southern blots demonstrating normal, random $X$ chromosome inactivation in $\mathrm{T}$ cells from mother 13 , and selective use of a single $\mathrm{X}$ as the active $\mathrm{X}$ in $\mathrm{T}$ cells from mother 12, are shown in Fig. 1.

Although none of the women included in this study had a past history of unusual or repeated infections, routine screening evaluations of the immune system were performed on blood from many of them because they were bone marrow donors for their sons. As expected, no significant abnormalities were found in the majority of these women; however, mother 12, who was shown in this study to be a carrier of $\mathrm{X}$-linked SCID based on nonrandom X chromosome inactivation in $\mathrm{T}$ cells, consistently had PBL counts of $<1,000$ / $\mathrm{mm}^{3}$, had proliferative responses to mitogens that were $\sim 20 \%$ of the control response, and had reduced proportions of CD3positive cells (38\%), CD4-positive cells (13\%), and CD8-positive cells (24\%). Because these abnormalities were not typically seen in carriers of X-linked SCID, additional cell lineages from this woman were analyzed.

Table I. X Chromosome Inactivation Patterns in T Cell Hybrids from the Mothers of Boys with Sporadic SCID

\begin{tabular}{|c|c|c|c|c|c|}
\hline $\begin{array}{l}\text { Patient } \\
\text { No. }\end{array}$ & $\begin{array}{c}\text { Hybrids } \\
\text { with large } \\
\text { allele }\end{array}$ & $\begin{array}{l}\text { Hybrids } \\
\text { with small } \\
\text { allele }\end{array}$ & Locus & $\begin{array}{c}\text { Odds ratio } \\
\text { carrier/normal* }\end{array}$ & Reference \\
\hline
\end{tabular}

Mothers with nonrandom $\mathrm{X}$ inactivation in $\mathrm{T}$ cells

$\begin{array}{rrrlr}4 & 22 & 0 & \text { DXS52 } & 87: 1 \\ 5 & 0 & 18 & \text { DXS7 } & 68: 1 \\ 6 & 0 & 15 & \text { DXS10 } & 51: 1 \\ 10 & 0 & 26 & \text { HPRT } & 101: 1 \\ 11 & 19 & 0 & \text { HPRT } & 73: 1 \\ 12 & 0 & 28 & \text { DXS86 } & 107: 1 \\ 15 & 0 & 19 & \text { DXS86 } & 73: 1\end{array}$

Mothers with random $\mathrm{X}$ inactivation in $\mathrm{T}$ cells

$\begin{array}{rrrlcl}1 & 5 & 11 & \text { DXS10 } & 0 & \\ 2 & 5 & 5 & \text { DXS3 } & 0 & \\ 3 & 7 & 14 & \text { DXS10 } & 0 & \\ 7 & 11 & 14 & \text { DXS3 } & 0 & \\ 8 & 19 & 14 & \text { HPRT } & 0 & \\ 9 & 3 & 6 & \text { DXS52 } & 0 & 12(1) \\ 13 & 10 & 25 & \text { DXS86 } & 0 & \\ 14 & 28 & 4 & \text { DXS1 } & 0.002: 1 & \\ 16 & 6 & 19 & \text { DXYS1 } & 0 & \end{array}$

* Probability that hybrids reflect negative selection against an $\mathrm{X}$ chromosome bearing a defective X-linked SCID gene vs. the null hypothesis of random $X$ inactivation.

$¥$ The first number is the reference cited. The number in parenthesis is the identifying patient designation in that reference. 

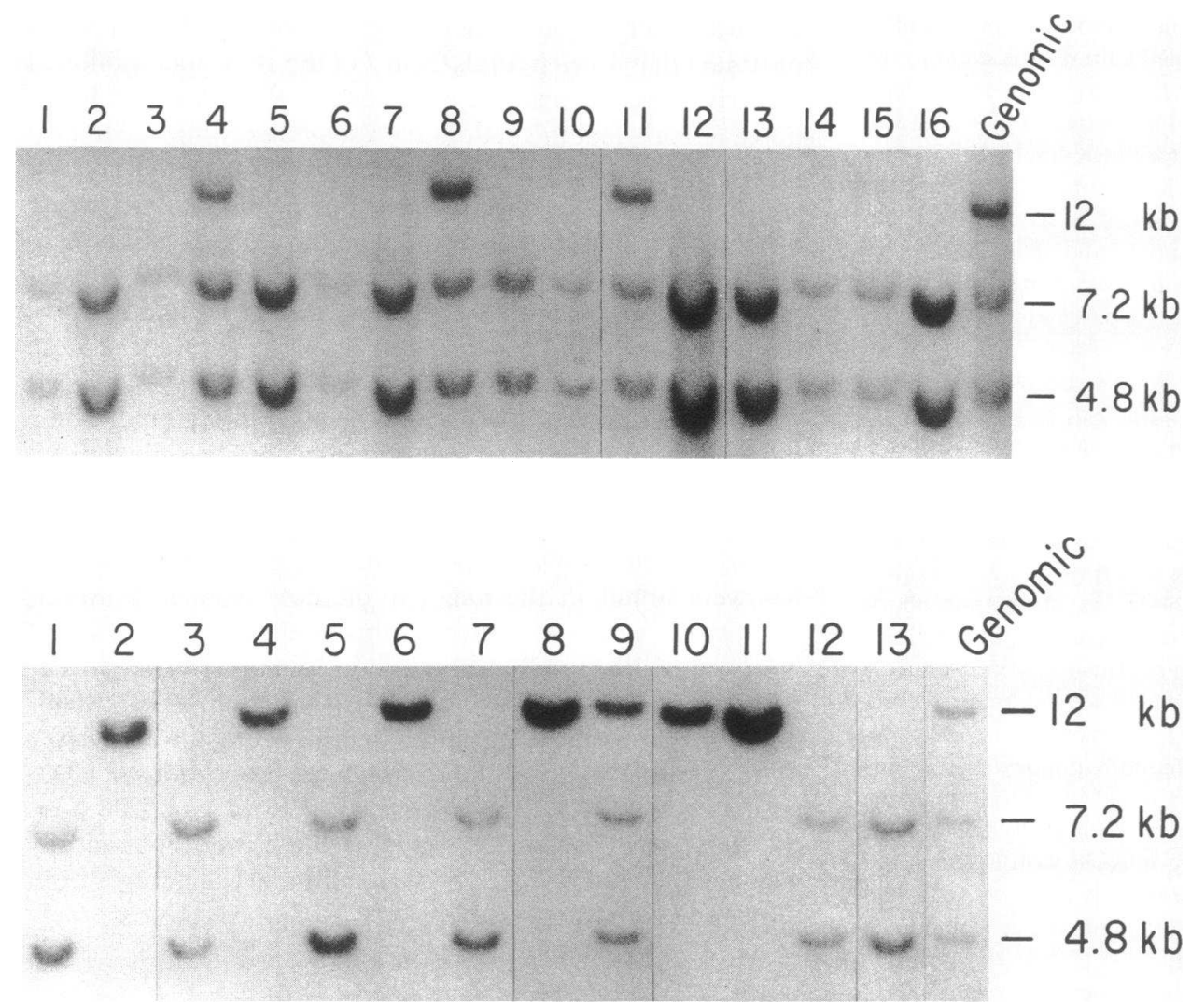

Figure 1. Patterns of $\mathrm{X}$ chromosome inactivation in $\mathrm{T}$ cell hybrids that selectively retain the active human X chromosome. Hybrids from two mothers of boys with sporadic SCID were analyzed with the probe St-1 which reveals an RFLP at the locus DXS86 when DNA is digested with the restriction enzyme Bgl II. One allele detected with this probe is a $12-\mathrm{kb}$ fragment and the other allele has an extra restriction site resulting in a two-fragment $7.2 / 4.8 \mathrm{~kb}$ allele. The genomic DNA is shown on the right in each Southern blot. The T cell hybrids from the mother of patient 12 (top) demonstrate exclusive use of a single $X$ as the active $X$. The hybrids in lanes 4,8 , and 11 contain both $X$ chromosomes. The remaining hybrids all contain the $\mathrm{X}$ chromosome with the extra restriction site. The $T$ cell hybrids from the mother of patient 13 (bottom) exhibit normal random $X$ chromosome inactivation with the hybrid in lane 9 containing both $\mathrm{X}$ chromosomes, the hybrids in lanes $2,4,6,8,10$, and 11 containing the $\mathrm{X}$ with the $12-\mathrm{kb}$ allele and the hybrids in lanes 1,3 , $5,7,12$ and 13 containing the $X$ with the extra restriction site.
Our past studies have shown that B cells as well as T cells from obligate carriers of X-linked SCID demonstrate nonrandom X chromosome inactivation, whereas phagocytes are unaffected by the gene defect and exhibit normal, random $X$ chromosome inactivation (9). Mother 12 was heterozygous for the RFLP at the $5^{\prime}$ end of the PGK gene, a locus near cytosine residues specifically methylated on the inactive $X(11)$. Therefore, we were able to evaluate $X$ chromosome inactivation patterns in this woman by methylation analysis. DNA from $T$ cells, B lineage cells, and neutrophils from this woman was digested with restriction endonucleases that would first reveal the polymorphism for PGK and second demonstrate whether the two $\mathrm{X}$ chromosomes were equally methylated. Although both $T$ and $B$ cells from this woman exhibited nonrandom $X$ chromosome inactivation, the neutrophils demonstrated normal, random $X$ chromosome inactivation confirming that subject 12 was a carrier of X-linked SCID.

To further explore inheritance of the gene defect in the seven women identified as carriers in this study, additional family members were evaluated. DNA was available from the affected sons of mothers 4 and 15 . In both cases, the male had inherited the RFLPs flanking the X-linked SCID locus on the maternal $X$ chromosome that was not used as the active $X$ in the $\mathrm{T}$ cell hybrids. $\mathrm{X}$ chromosome inactivation patterns from the four daughters of mothers 5,11 , and 12 were evaluated. Three of these four females at 50\% risk of being carriers exhibited nonrandom $\mathrm{X}$ chromosome inactivation in $\mathrm{T}$ cell hybrids, indicating that they too were carriers of X-linked SCID. In each case, the inactive $X$ was the maternally derived $X$ bearing the defective X-linked SCID locus. The daughter of mother 12, who demonstrated normal random $X$ chromosome inactivation in her $T$ cells, had inherited the maternal $X$ bearing the normal X-linked SCID locus.

The parents of mothers $4,5,6$, and 12 were available for study, permitting us to investigate the origin of the gene defect in these families. The maternal grandmothers in families 4,5 , and 6 demonstrated normal, random $X$ inactivation in their $T$ cells, suggesting that the gene defect occurred as a new mutation in the patients' mothers. In two of these cases, DNA analysis demonstrated that the defective $X$, the inactive $X$ in $T$ cell hybrids, was derived from the maternal grandfather and in one case from the maternal grandmother. In contrast, $T$ cells from the mother of mother 12 demonstrated exclusive use of a single $X$ as the active $X$ in all 21 T cell hybrids, indicating that this woman was also a carrier of X-linked SCID. This woman's two sons, the brothers of mother 12 , had both inherited the X-linked SCID locus on the normal X, the active $\mathrm{X}$ in the $\mathrm{T}$ cell hybrids, whereas mother 12 had inherited the X-linked SCID locus from the mutant, inactive $X$. T cell hybrids from the maternal grandmother of mother 12 , the great-grandmother of the patient, demonstrated normal, random X chromosome inactivation with eight hybrids having one $X$ as the active $X$ and four hybrids having the other $X$ as the active $X$.

To determine whether there were any clinical or laboratory characteristics that might help differentiate the boys whose mothers were identified as carriers of X-linked SCID from 


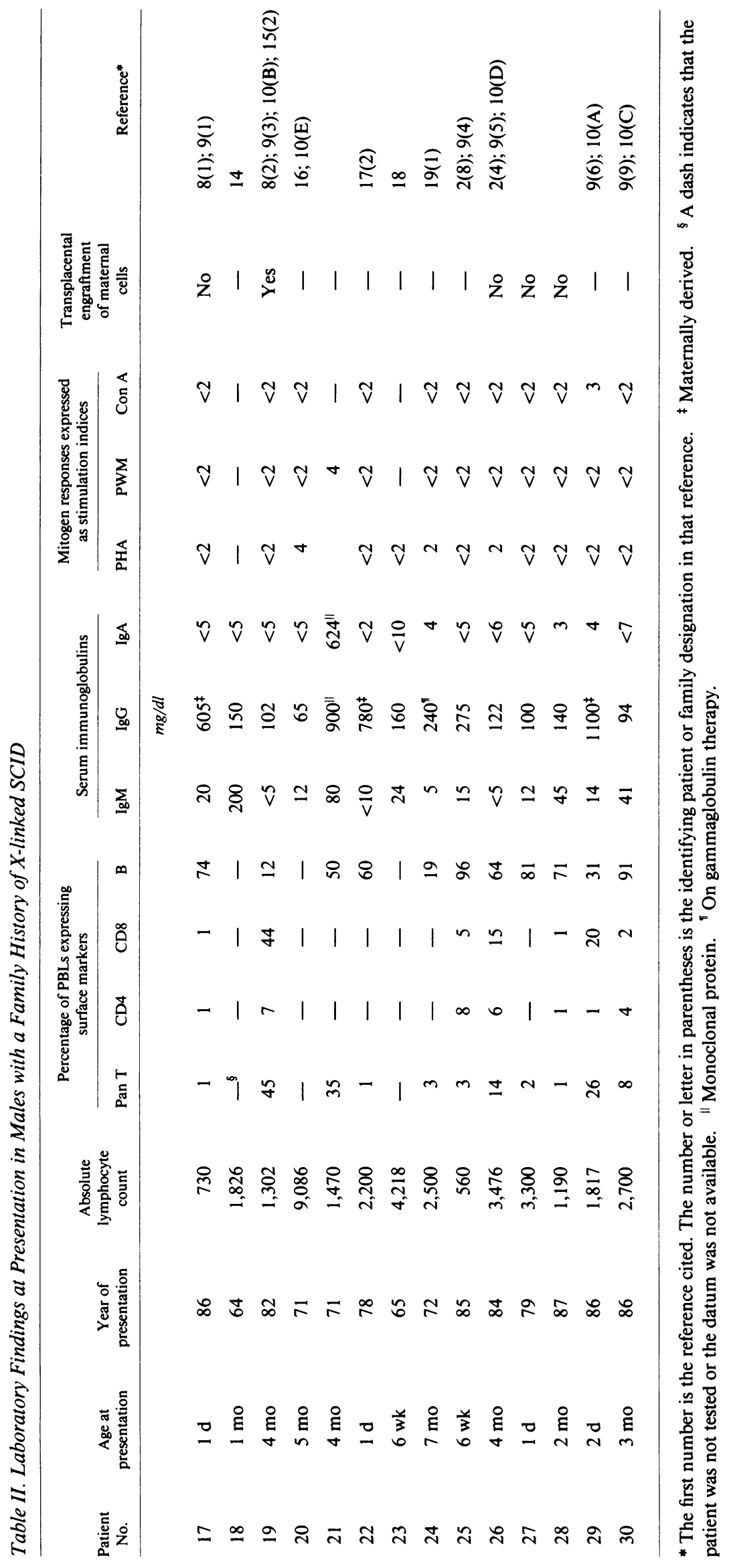




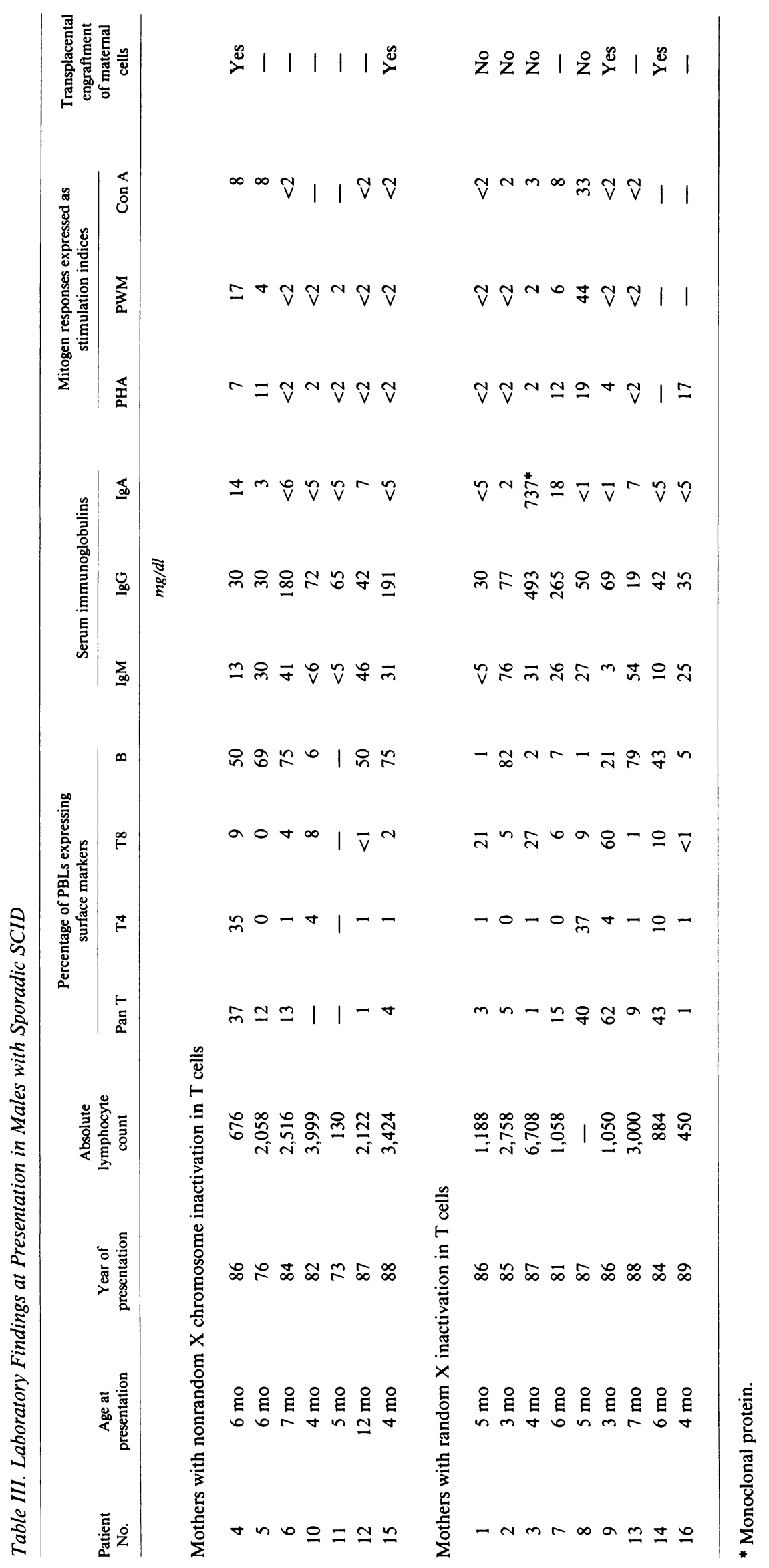


those whose mothers were not, we examined the clinical records of both groups and compared them to each other and to those from boys with a family history of X-linked SCID (Tables II and III). All patients except patient 12 presented to medical attention before 8 mo of age. Most patients were mildly lymphopenic. Six patients, two with a family history of $\mathrm{X}$-linked SCID, one identified in this study as having X-linked SCID, and three with SCID of undetermined genetic origin, differed from the others in that $>30 \%$ of their peripheral blood lymphocytes were $T$ cells. Spontaneous engraftment of maternal $\mathrm{T}$ cells, acquired either transplacentally or during the birth process, was demonstrated by HLA or karyotype analysis in three of these infants. Of the remaining three patients, two were not evaluated for maternal engraftment and in one patient with SCID of undetermined genetic type, the $T$ cells were of host origin. Proliferation in response to mitogens was markedly decreased or absent in all of the patients with a family history of X-linked SCID. Four of the patients with sporadic SCID had slightly higher stimulation indices. Two of these patients were shown to have X-linked SCID based on nonrandom $X$ chromosome inactivation in $T$ cells from their mothers; however, one of these patients also had spontaneous maternal engraftment.

Concentrations of serum immunoglobulins did not discriminate between the different groups. There were patients in each group who had concentrations of serum IgM close to or within the normal range. There was one patient with a family history of X-linked SCID and one patient with sporadic SCID who had monoclonal immunoglobulin proteins. In patients beyond the neonatal period the serum IgG was decreased in all patients.

All of the patients in the group with a family history of X-linked SCID had elevated proportions of B cells with the exception of the patient with known engraftment of maternal $T$ cells. In the group of patients with sporadic SCID, there was more heterogeneity. Five of the six boys whose mothers were identified as carriers of X-linked SCID, and for whom B cell numbers were available, also had elevated proportions of $B$ cells; $6 \%$ of the remaining boy's peripheral blood lymphocytes were B cells as identified by immunofluorescence staining for surface IgM. Only four of the nine patients whose mothers demonstrated random inactivation of the $X$ chromosome in $T$ cells had elevated numbers of $B$ cells. Two of these four patients had spontaneous engraftment of maternal $\mathrm{T}$ cells.

\section{Discussion}

In 1935, Haldane suggested that as many as half of the males with a lethal X-linked disorder may not have any family history of that disorder because they represent the first expression of a new mutation (21). He pointed out that a third of all $\mathrm{X}$ chromosomes are in males. If that third is lost each generation, as would be expected for an X-linked lethal disorder, and if the frequency of the defect remains constant, then there must be an equal number of new mutations to compensate for those lost. New mutations that occur in females would be silent in $\mathrm{X}$-linked recessive disorders. Therefore, both males with new mutations and the sons of females with new mutations will have no family history of the disorder. In well-characterized $\mathrm{X}$-linked disorders that are lethal without medical interven- tion, such as hemophilia and $\mathrm{X}$-linked agammaglobulinemia (Bruton's agammaglobulinemia), between a third and half of the affected males have no family history of the disorder $(22,23)$.

Of the 16 women that we studied who had had sons with SCID but no other affected family members, 7 could be identified as carriers of X-linked SCID based on nonrandom X chromosome inactivation in their $\mathrm{T}$ cells. Studies on additional family members reinforced this diagnosis. Three of the four daughters of the carrier women were shown to have nonrandom $\mathrm{X}$ chromosome inactivation in their T cells, indicating that these females were also carriers. Linkage studies demonstrated that the carrier daughters and the affected sons had inherited the defective maternal X-linked SCID locus. That is, each had inherited the X-linked SCID locus on the X chromosome that was consistently inactive in the maternal $\mathrm{T}$ cell hybrids. The source of new X-linked SCID mutations could be identified in three of the families. In two cases, the defective $\mathrm{X}$ was derived from the maternal grandfather and in one case from the maternal grandmother.

It is possible that some of the boys with SCID whose mothers' $T$ cells exhibited random $X$ inactivation may also have had X-linked SCID, occurring as a new mutation in the ovum from which the boy developed. If new mutations occur in both maternally and paternally derived X chromosomes, one would expect there to be some males with X-linked SCID whose mothers were not carriers. Patients 2 and 13 (Table III) could represent such new mutations, as their pretransplant laboratory studies are most similar to those of patients known to have X-linked SCID.

In this study, data have been compiled on 21 patients with $\mathrm{X}$-linked SCID. Although there was no single clinical or laboratory characteristic that always distinguished patients who had inherited X-linked SCID from patients who were less likely to have inherited X-linked forms of the disorder, there was a distinct trend. Most of the patients with a family history of X-linked SCID and most of the patients identified as having $\mathrm{X}$-linked SCID in this study had markedly reduced numbers of $T$ cells, absent proliferative responses to mitogens, very low serum IgG and IgA with variable concentrations of serum IgM and elevated proportions of B cells. Elevated proportions of B cells were the most consistent finding. Exceptions to this paradigm could frequently be attributed to transplacental engraftment of maternal $T$ cells, indicating that such engraftment can obscure the underlying genetic defect. Attempts to classify the genetic basis of SCID are further complicated by the observation that there are females with SCID who have laboratory findings similar to those described above $(2,17)$. In the absence of Turner's syndrome or karyotypic abnormalities such as translocation, these females indicate that there is at least one autosomal recessive form of SCID that results in a clinical and laboratory presentation identical to that of X-linked SCID. Clarification of the relationship between such an autosomal recessive gene and the gene for typical X-linked SCID should provide useful information about the development of the normal immune system.

Studies from our laboratory and others have mapped the gene for X-linked SCID to the proximal part of the long arm of the $\mathrm{X}$ chromosome at Xq13.1-q21.1 (10, 24). In families who are known to be at risk for X-linked SCID, use of RFLPs 
linked to the gene defect will permit carrier detection and prenatal diagnosis. However, because of the high frequency of new mutations in this disorder, there will always be male infants without a family of SCID for whom it is not clear whether they have inherited an X-linked or autosomal recessive form of the disease. For the families of these boys, analysis of $\mathrm{X}$ chromosome inactivation patterns in maternal $\mathrm{T}$ cells will help clarify future risks for members of the family and will also aid in the design of appropriate therapy for the child, particularly when gene therapy becomes available.

\section{Acknowledgments}

These studies were supported in part by the Immune Deficiency Foundation, March of Dimes Basic Research grant 1077, National Institutes of Health grants AI-25129, HD-23679, and CA-21765, and American Lebanese Syrian Associated Charities.

\section{References}

1. Gelfand, E. W., and H. M. Dosch. 1983. Diagnosis and classification of severe combined immunodeficiency disease. Birth Defects Orig. Artic. Ser. 19:65-72.

2. Buckley, R. H., S. E. Schiff, H. A. Sampson, R. I. Schiff, M. L. Markert, A. P. Knutsen, M. S. Hershfield, A. T. Huang, G. H. Mickey, and F. E. Ward. 1986. Development of immunity in human severe primary $\mathrm{T}$ cell deficiency following haploidentical bone marrow stem cell transplantation. J. Immunol. 136:2398-2407.

3. Ammann, A. J., and R. Hong. 1989. Disorders of the T cell system. In Immunologic Disorders in Infants and Children. E. R. Stiehm, editor. W. B. Saunders Company, Philadelphia. 257-315.

4. Hirschhorn, R. 1983. Genetic deficiencies of adenosine deaminase and purine nucleoside phosphorylase: overview, genetic heterogeneity and therapy. Birth Defects Orig. Artic. Ser. 19:73-81.

5. Markert, M. L., M. S. Hershfield, R. I. Schiff, and R. H. Buckley. 1987. Adenosine deaminase and purine nucleoside phosphorylase deficiencies: evaluation of therapeutic interventions in eight patients. $J$. Clin. Immunol. 7:389-399.

6. Reith, W., S. Satola, C. Herrero Sanchez, I. Amaldi, B. Lisowska-Grospierre, C. Griscelli, M. R. Hadam, and B. Mach. 1988. Congenital immunodeficiency with a regulatory defect in MHC class II gene expression lacks a specific HLA-DR promoter binding protein, RF-X. Cell. 53:897-906.

7. Mandel, J.-L., H. F. Willard, R. L. Nussbaum, G. Romeo, J. M. Puck, and K. E. Davies. 1989. Report of the committee on the genetic constitution of the X chromosome. Cytogenet. Cell Genet. 51:384437.

8. Puck, J. M., R. L. Nussbaum, and M. E. Conley. 1987. Carrier detection in X-linked severe combined immunodeficiency based on patterns of X chromosome inactivation. J. Clin. Invest. 79:1395-1400.

9. Conley, M. E., A. Lavoie, C. Briggs, P. Brown, C. Guerra, and J. M. Puck. 1988. Nonrandom X chromosome inactivation in B cells from carriers of $\mathrm{X}$ chromosome-linked severe combined immunodeficiency. Proc. Natl. Acad. Sci. USA. 85:3090-3094.
10. Puck, J. M., R. L. Nussbaum, D. L. Smead, and M. E. Conley. 1989. X-linked severe combined immunodeficiency: localization within the region Xq13.1-q21.1 by linkage and deletion analysis. $\mathrm{Am}$. J. Hum. Genet. 44:724-730.

11. Vogelstein, B., E. R. Fearon, S. R. Hamilton, A. C. Preisinger, H. F. Willard, A. M. Michelson, A. D. Riggs, and S. H. Orkin. 1987. Clonal analysis using recombinant DNA probes from the X-chromosome. Cancer Res. 47:4806-4813.

12. Barrett, M. J., R. H. Buckley, S. E. Schiff, P. C. Kidd, and F. E. Ward. 1988. Accelerated development of immunity following transplantation of maternal marrow stem cells into infants with severe combined immunodeficiency and transplacentally acquired lymphoid chimerism. Clin. Exp. Immunol. 72:118-123.

13. Moen, R. C., S. D. Horowitz, P. M. Sondel, W. R. Borcherding, M. E. Trigg, R. Billing, and R. Hong. 1987. Immunologic reconstitution after haploidentical bone marrow transplantation for immune deficiency disorders: treatment of bone marrow cells with monoclonal antibody CT-2 and complement. Blood. 70:664-669.

14. Fireman, P., H. A. Johnson, and D. Gitlin. 1966. Presence of plasma cells and $\gamma_{1}$ M-globulin synthesis in a patient with thymic alymphoplasia. Pediatrics. 37:485-492.

15. Conley, M. E., P. C. Nowell, G. Henle, and S. D. Douglas. 1984. XX T cells and XY B cells in two patients with severe combined immune deficiency. Clin. Immunol. Immunopathol. 31:87-95.

16. Goldblum, R. M., R. A. Lord, E. Dupree, A. G. Weinberg, and A. S. Goldman. 1973. Transfer factor induced delayed hypersensitivity in X-linked combined immunodeficiency. Cell. Immunol. 9:297-305.

17. Griscelli, C., A. Durandy, J. L. Virelizier, J. J. Ballet, and F. Daguillard. 1978. Selective defect of precursor $T$ cells associated with apparently normal B lymphocytes in severe combined immunodeficiency disease. J. Pediatr. 93:404-411.

18. Miller, M. E. 1967. Thymic dysplasia ("Swiss agammaglobulinemia"). J. Pediatr. 70:730-736.

19. Buckley, R. H., R. B. Gilbertsen, R. I. Schiff, E. Ferreira, S. O. Sanal, and T. A. Waldmann. 1976. Heterogeneity of lymphocyte subpopulations in severe combined immunodeficiency. Evidence against a stem cell defect. J. Clin. Invest. 58:130-136.

20. Reisner, Y., N. Kapoor, D. Kirkpatrick, M. S. Pollack, S. Cunningham-Rundles, B. Dupont, M. Z. Hodes, R. A. Good, and R. J. O'Reilly. 1983. Transplantation for severe combined immunodeficiency with HLA-A, B, D, DR incompatible paternal marrow cells fractioned by soybean agglutinin and sheep red blood cells. Blood. 61:341-348.

21. Haldane, J. B. S. 1935. The rate of spontaneous mutation of a human gene. J. Genet. 31:317-326.

22. Bithell, T. C. 1987. Disorders of blood coagulation. In Fundamentals of Clinical Hematology. O. A. Thorup, T. C. Bithell, C. E. Hess, R. P. Keeling, D. N. Mohler, E. Niskanen, P. J. Quesenberry, R. E. Smith, and M. S. Wheby, editors. W. B. Saunders Company, Philadelphia. 824-876.

23. Lederman, H. M., and J. A. Winkelstein. 1985. X-linked agammaglobulinemia: An analysis of 96 patients. Medicine (Baltimore). 64:145-156.

24. de Saint Basile, G., B. Arveiler, I. Oberle, S. Malcolm, R. J. Levinsky, Y. L. Lau, M. Hofker, M. Debre, A. Fischer, C. Griscelli, and J. L. Mandel. 1987. Close linkage of the locus for X chromosomelinked severe combined immunodeficiency to polymorphic DNA markers in Xq11-q13. Proc. Natl. Acad. Sci. USA. 84:7576-7579. 